teeth. These are forms for fuller information upon which we anxiously wait.

The negative evidence (which of course must be received with the greatest caution in palæontology) of the absence of remains of any of these animals in the true Miocene or Pliocene deposits of North America, indicates that the race became extinct at least in that land, though it possibly may have emigrated elsewhere, and perhaps in Asia, may have laid the foundation of that family which first appears in the Old World under the more familiar aspect of typical Proboscideans. While, however, there are no grounds for assuming that the latter were derived directly from the Eocene Bathmodons and Uintatheriums, it is not too much to look upon these as affording some indications of the steps by which the process might have taken place, and, as such, their discovery is one of the most interesting that has been revealed by modern palæontological research.

It should be mentioned that Marsh, who has given us very full information upon the osteology and dentition of this group, has made of Uintatherinm and its immediate allies a peculiar order of mammals, to which he gives the name of Dinocerata, while Cope, who formerly included them in the Proboscidea, and placed Bathmodon and its allies in the Perissodactyla, has recently formed an order called Amblypoda, containing two sub-orders, of which Dinocerata is one, and Pantodonta (Bathmodon and Metalophodon ) the other.

The tertiaries of South America have yielded some very remarkable forms of mammalian life, the nature and affinities of which have greatly puzzled all zoologists who have attempted to unravel them. Macrauchenia has been already described among the Perissodactyle Ungulates, of which group it is undoubtedly a member, although in some characters somewhat aberrant. The articulation of the fibula with the calcaneum is an Artiodactyle, or perhaps generalised character. The teeth ally it to Palæotherium and Rhinoceros. Homalodontotherinu from the banks of the River ( iallegos, South-east Patagonia, is known by the teeth alone, which, though very generalised, are on the whole rhinocerotic. Nesodon, from the same locality, also only known by the dentition and some parts of the skull, connects the last and Macrauchenia with Toxodon. These three genera have the typical dental formula of $i \frac{3}{3}<\frac{1}{1} p \frac{4}{4} m \frac{3}{3}=44$. Toxodon is an animal about the size of a hippopotamus, of which many specimens have now been found in Pleis. tocene deposits near Buenos Ayres, which have been described by Owen, Gervais, and Burmeister. The teeth consist of incisors, very small lower canines, and strongly curved molars, all with persistent roots; the formula being apparently $i \frac{2}{3} c \frac{0}{1} p \frac{4}{3} m \frac{3}{3}=38$. The cranial characters exhibited a combination of those found in both Perissodactyles and Artiodactyles, but the form of the hinder part of the palate, the absence of an alisphenoid canal, and especially the tympanic being firmly fixed in between the squamosal and the exoccipital, ankylosed to both, and forming the floor of a long, upward directed meatus auditorius, is so exactly like that of the Suina, that it is difficult to believe that it does not indicate some real affinity to that group. These characters seem to outweigh in importance those by which some zoologists have linked it to the Perissodactyla, and the absence of the third trochanter, and the articulation of the fibula with the calcaneum tell in the same direction. The structure of the feet is not known, but it is probable that it had five toes on each.

Mesothernum, Serres, also called Typotherium by Bravard and Gervais, was an animal rather larger than a Capybara, and of much the same general appearance. Its skeleton is completely known, and shows a singular combination of characters, resembling Toxodon, or a generalised Ungulate on the one hand, and the Rodents, especially the Leporida on the other. In the presence of clavicles, of five toes on the fore-foot and four on the hinder, it differs from all existing Ungulates, and yet if it is considered as a Rodent, it must be looked upon as a most aberrant form. The teeth are $i \frac{\mathrm{I}}{2} c \frac{\mathrm{O}}{\mathrm{O}} p \frac{2}{\mathrm{I}}$ $m \frac{3}{3}=24$ Although our knowledge of many of these forms is still very limited, we may trace among them a curious chain of affinities, which, if correctly interpreted, would seem to unite the Ungulates on the one hand, with the Rodents on the other; but further materials are needed before we can establish with certainty so important a relationship, one which, if true, would alter materially some of the prevailing views upon the classification of mammals. It may be convenient provisionally to include those Ungulates which are neither Artiodactyla nor Perissodactyla, under a third heading, of which Poly dactyla ${ }^{1}$ would be the appropriate designation; though there is no evidence that they form such a homogeneous group as either of the other two.

( $T o$ be continued.)

PROF. HUXLEY'S LECTURES ON THE EVI DENCE AS TO THE ORIGIN OF EXISTING VERTEBRATE ANIMALS ${ }^{2}$

I.

TWENTY years ago the arguments as to the causes of the phenomena of organic nature, brought forward in support of the then recently advanced views of $\mathrm{Mr}$. Darwin, were largely speculative; all one could hope to show was that no valid objections could be urged against the theory of evolution. But since that time "many have run to and fro and knowledge has been increased"; the question has come out of the region of speculation into that of proof ; every day increases our familiarity with the phenomena of life on the globe in antecedent ages, and so gives us the only valid evidence obtainable as to the evolution of living things.

When we consider any animal at the present day there are three hypotheses which may be put forward with regard to its origin: that it arose out of nothing, that it had its origin from dead inorganic matter, or that it arose as a modification of some pre-existing living being. It is hardly worth while to consider the two first of these hypotheses - for the first it would be utterly impossible to obtain any evidence, and the second is devoid of all ground of analogy, and opposed to all our knowledge of what actually takes place. The last, on the other hand, should, if true, be capable of some sort of proof--at any rate it can be brought to the test of facts.

It is quite conceivable that all evidence as to the origin of an animal may have disappeared, and that the problem becomes, in consequence, insoluble by direct evidence, analogy and probability being the only guides left. As a matter of fact, however, we possess in the 70,000 feet of stone, gravel, sand, \&c., which form the earth's crust, fossil remains imbedded in chronological order, and in many cases so perfectly preserved, that all important details can be made out almost as well as in the recent state.

The plan adopted in these lectures will be not to give all obtainable evidence with regard to the origin of each group of vertebrate animals, but to select from each class one or two definite cases of living animals, and to see what evidences can be obtained, by going back in time, as to the way in which they have come about, or at any rate as to the extent of the duration of their existence.

s An extension of the order Toxolontic of Owen, and Ungulata multidigituf ${ }^{2}$ of Burmeister. 2 A course of six lcctures to working men, ilelivercd in the theatre of the
Royal School of Mines. Lecture I., Feb. 28 . 
To begin with fishes : we will take as our first example the very beautiful genus Beryx, a fish not unlike our seabream, found widely distributed through the deep seas, and extending to about $40^{\circ}$ on each side of the equator. Like the perch or the sea-bream, it is a greatly specialised fish; the head is immensely large, the bony rays supporting the fins hard and unjointed, the ventral fins or representatives of the hind limbs situated just behind the head, under the throat, the operculum curiously ornamented, and the air-bladder completely shut off from the gullet; thus differing very markedly from a more generalised fish such as the herring or carp, in which the head is proportionally much smaller, the fin-rays soft and jointed, the ventral fins far back, the operculum not ornamented, and the air-bladder communicating by a duct with the œsophagus.

We now know that at depths greater than five or six hundred fathoms, the sea-bottom is to a great extent composed of a very fine greyish-white mud, sticky when first removed from the water, but afterwards hardening into a delicate friable stone, not at all unlike chalk. This mud, which is largely made up of shells of the minute marine organism Globigerina, forms the bed of thousands of square miles of sea in which Beryx lives, and there can be no doubt that when the fish dies it sinks to the bottom, and, its soft parts being destroyed, becomes gradually imbedded in the soft mud, there to remain until the present sea-bottom is upheaved and becomes dry land.

Now, as a matter of archæological evidence, what is known of the history of Beryx and of the source whence it proceeded? Naturally it is useless to seek for such evidence except in deposits formed under like conditions to those in which the fish lives at the present day. Through the whole of the Pliocene and Miocene epochs no deep-sea formations are known, but in the middle of the Eocene period-a time so remote that tropical plants flourished on the banks of the Thames, and croccdiles abounded in this country - we are acquainted with an extensive deepsea deposit, the Nummulitic limestone, which, besides the fossil giving it its name, contains large quantities of Globigerina, in all essential respects like that of the present day. In this formation are found two forms closely allied to Beryx, but with such slight differences as to receive different generic names; these are known as Acanus and Pristigaster. On passing from the Eocene or lowest tertiary to the chalk or uppermost secondary formation, which bears the closest possible resemblance to the modern Atlantic mud-the two may, in fact, be looked upon as belonging to one continuous series of deposits-we find an actual Beryx, a fish differing no more from the modern Berices than the various modern species of Beryx do from one another. This fossil, owing to the fineness of the chalk-forming mud in which it was buried, is so perfectly preserved, that all the details of structure of its hard parts, even to the ornamentation of the scales, can be compared with those in the recent fish ; and in this way the most conclusive evidence is obtained that the differences which separate it from its modern relatives are of no greater importance than those by which the recent species of Beryx are distinguished from one another.

Thus we have positive evidence that a fish altogether like the Beryx of the present day, existed millions of years ago, before the Alps, the Himalayas, or the Rocky Mountains were upheaved, and has continued to live ever since. In face of these facts we cannot but conclude that the In face of these factived from that of the chalk, and that the hypotheses of its creation out of nothing, and of its origin from inorganic matter are, for scientific purposes, simply non-existant.

As to the form from which the Beryx of the chalk was derived, we have absolutely no evidence, for there is no trace of any such fish in any lower formation.

We now pass on to a fish of a far older and less specialised type than Beryx-the genus Ceratodus, recently discovered in Australia. This animal, which attains a length of six feet, is distinguished by the possession of very curious fins, consisting of a central lobe, with a surrounding fringe of fin-rays, and by the character of its teeth, which are produced into curious horn-like processes, so arranged that those of opposite jaws interlock. Ceratodus is probably a vegetable feeder, lives in fresh or brackish water, and is said sometimes to leave its native element and crawl about among the weeds on the bank. It is enabled to do this by the fact that it can breathe air directly as well as air dissolved in water; it has, in fact, besides gills, an organ which is altogether a half-way house between the air-bladder of a fish and the lung of an amphibian.

In the Wealden, the most recent estuarine deposit of which we have any knowledge, there is no trace of Ceratodus to be found, but this is hardly surprising, as only two or three small patches of the earth's surface formed at this epoch have been examined, and animals have a geographical distribution at all times. But on passing back to the Trias, a formation as far from the chalk in point of time as the chalk from the present day, we find teeth belonging to an undoubted Ceratodus, in shape and in microscopic strurture, exactly like those of the modern Australian fish. No other remains of the Triassic Ceratodus have as yet been found, but teeth are known to be so important a diagnostic character that no naturalist would have any hesitation in naming the genus to which the fish bearing such teeth should be assigned.

Thus we have a far more astonishing example of a persistent type than was afforded by our Beryx, and as in the case of the latter fish, all trace of the actual genus Ceratodus is lost at this point, and we are obliged to content ourselves with a few singular hints as to the way in which the type has come about. The most valuable of these hints are obtained by a study of a singular group of fish found in great abundance in the Old Red Sandstone. These are distinguished by the possession of curious fringed fins, unlike those of any other fish except Lepidosiren and Ceratodus-in fact, one genus, Dipterus, has fins quite like those of Ceratodus, and its teeth and skeleton were formed on just the same type. It is doubtful whether there is any relation between Ceratodus and Dipterus in the way of ancestry, but the resemblance between them is remarkable.

It must seem rather strange for a known evolutionist to select as examples two fish like Beryx and Ceratodus, which, of all others, seem most likely to support the notion that species are immutable. The adverse side only of the question has been stated to-night, the other side will be treated of on future occasions.

\section{THE OLD RED SANDSTONE}

$A T$ a meeting of the Glasgow Geological Society on $A$ the 24th ult., Sir William Thomson, F.R.S., president, in the chair, Prof. Geikie, F.R.S., communicated the results of recent researches into the "History of the Deposits known as the Old Red Sandstone." After a preliminary outline of our present knowledge on the subject, he proceeded to consider the development of the Oid Red Sandstone in the British Isles under its accepted threefold division into Lower, Middle, and Upper. The Lower member, wherever its true base can be seen, is found to pass down conformably into the Upper Silurian rocks. But a well-marked line of demarcation, both by physical characters and fossil evidence, runs between the two systems. The Silurian formations continue replete with organic remains up to their uppermost zone; but on entering the red strata of the overlying system we meet with a remarkably abrupt change, for the fossils almost wholly disappear, and those which occur belong for the 